\title{
Proceso de actualización de un ensayo de Roberto Bolaño*
}

\author{
Actualization process of an essay written by Roberto Bolaño \\ Jorge Lagos Caamaño ${ }^{1}$, Daniel Rojas Pachas ${ }^{2}$ \\ ${ }^{1}$ Universidad de Tarapacá, Departamento de Español, Arica Chile. Correo electrónico: jlagos@uta.cl \\ ${ }^{2}$ Universidad de Tarapacá, Departamento de Español, Arica Chile. \\ Correo electrónico: carrollera@gmail.com
}

Este trabajo se propone (re)construir el Lector Modelo del texto "El Exilio y la Literatura" a través del cruce entre las estrategias textuales de construcción del ensayo y el modelo metatextual de Umberto Eco.

Palabras clave: lector modelo, ensayo, fragmentación, intertextualidad, ironía.

The present work intends to (re)construct the Model Reader of the text "Exile and Literature" through the relation among the textual construction strategies of the essay and Umberto Eco's metatextual model.

Key words: model reader, essay, fragmentation, intertextuality, irony.

\section{INTRODUCCIÓN}

El presente trabajo tiene por finalidad analizar cómo el ensayo literario de Roberto Bolaño, “El Exilio y la Literatura” (2001), exige para su interpretación -tal como lo indica Umberto Eco (1981) en su modelo metatextual emanado de los niveles de cooperación textual- la realización de una serie de pasos complejos, paseos inferenciales, búsquedas ideológicas, revisión de aspectos estructurales y aprovechamiento de conocimientos previos recurriendo a la enciclopedia personal y a información externa. Por ello, se plantea como hipótesis que el Lector Modelo de "El exilio y la Literatura” se (re)construye a partir de la (re)organización textual fragmentaria, intertextual e irónica del texto, conceptos que Martín Cerda (1982, 1993, 1997) desarrolla en sus obras a fin de caracterizar el género ensayístico.

* $\quad$ Este trabajo es parte de la tesis de Magíster en Ciencias de la Comunicación (2012) de Daniel Rojas y producto del Proyecto de Investigación Mayor Ciencia y Tecnología No 5740-10 de la Universidad de Tarapacá de Arica dirigido por Jorge Lagos, Jefe de Proyecto, Ana María Soza, Investigador Principal, Daniel Rojas y Sebastián Zepeda, Investigadores Asociados. 
La presencia de estas estrategias textuales determina, de acuerdo a la hipótesis planteada, la compleja cooperación textual que el eventual lector empírico debe realizar frente al escrito de Bolaño antes mencionado y ante otros corpus textuales del género del mismo autor, tales como "Literatura + enfermedad = enfermedad" (2003) y “Déjenlo todo nuevamente. Primer manifiesto infrarrealista” (1976), que se tendrán como punto de referencia.

\section{CONSIDERACIONES PRELIMINARES}

Roberto Bolaño (1953-2003) fue un escritor chileno nómade en su vida y escritura. Gran parte de su crecimiento como autor lo realizó en México y España, pero siempre vinculado a nuestro continente y a su Chile natal. Esta experiencia móvil y multifacética, plagada de atmósferas y discursos, mitos y desacralizaciones de grandes figuras e instituciones que alimentan con lugares comunes nuestra visión de la literatura, forman parte de su estilo y nutren su devenir poético, narrativo y ensayístico. Encontramos como tópicos en su literatura el viaje, el carácter errante del ser humano y el desprendimiento de muchas convenciones y ataduras sociales, al punto de llegar a la marginalidad, tanto así que la selección de personajes y voces inusuales que Bolaño edifica a la hora de diseñar sus mundos ficticios, conforma un universo textual caracterizado por un cúmulo de entrañables detectives, pornógrafos, sicarios, jóvenes perdidos en grandes ciudades, traficantes, asesinos en serie, fascistas, hombres de fe en contubernio con el poder y artistas esquizofrénicos, todos cruzados por una peculiar obsesión, a saber, los vasos comunicantes que subyacen entre el arte en todas sus manifestaciones y la violencia más cruel ${ }^{1}$.

$\mathrm{Su}$ obra es, por tanto, un guiño constante al oficio obsesivo y degradante del creador, al proceso que se sufre al asumir la apuesta total de la escritura, y en tal medida existe en el grueso de su bibliografía una revisión permanente de la figura del hombre y mujer que escriben; como dice Blanchot, a propósito de Baudelaire y muchos románticos alemanes:

casi todos (...) intentaron sustituir la nostalgia de una totalidad perdida por la utopía de un libro total, del que cada uno de ellos dejó sólo algunos fragmentos adensados, temblorosos, casi trágicos. Rastro de un esfuerzo fallido, sombra de ese libro total, el fragmentario romántico fue una forma estéticamente válida y, a la vez, el producto de una science du monde insuficiente (1955: 55, cursivas nuestras).

\footnotetext{
Las vinculaciones intertextuales que Bolaño despliega prefiguran una concepción apocalíptica. Pesadillas de un infierno, suma de nuestra violencia afincada en las fronteras de la realidad: “(...) la Guerrero, a esa hora, se parece sobre todas las cosas a un cementerio, pero no a un cementerio de 1974, ni a un cementerio de 1968, ni a un cementerio de 1975, sino a un cementerio del año 2666, un cementerio olvidado debajo de un párpado muerto o nonato, las acuosidades desapasionadas de un ojo que por querer olvidar algo ha terminado por olvidarlo todo" (Bolaño 2002: 76-77). Este párrafo lo podemos vincular a una concepción estética de la maldad que el investigador Alexis Candia reconoce en la obra de Bolaño. Su estudio de "2666: La magia y el mal”, expone cómo Bolaño en sus textos establece vasos comunicantes con presupuestos de Bataille, la idea de sexualidad artificial, cierta bruma dionisíaca que se respira en todo la obra y, principalmente, una continua alusión a Sade y la educación sentimental que la lectura del francés proveyó al escritor chileno. Esto va de la mano con las parodias y reinterpretaciones que el autor hace de figuras canónicas del mundo cultural de occidente y Chile (Alone, Valente, Zurita, Paz, Neruda, Jodorowski, Rimbaud, Kafka, Perec, etc).
} 
Bolaño, en tal medida, se muestra como un autor prolífico y abierto a una variedad de géneros como creador; su literatura se sustenta en el fragmento y la intertextualidad, en los cruces inesperados y el dialogismo que entablan sus poemas con las prosas y viceversa. ${ }^{2}$

\subsection{Estrategias textuales del género ensayo}

\subsubsection{Fragmentación}

La fragmentación en el ensayo podemos entenderla, desde la perspectiva de Martín Cerda, como una tradición que se ha sustantivado y diversificado en los escritos de algunos de los ensayistas más significativos del siglo XX: Walter Benjamin, Michel Leiris, Theodor W. Adorno, Maurice Blanchot, E.M. Cioran, Roland Barthes y Kostas Axelos (Cerda 1982: 9). El ensayo como género demuestra que no estamos ante un código cerrado bajo la fórmula vertical de la linealidad: presentación, conflicto o nudo y desenlace. En su enunciación, incluso, el carácter exploratorio y propositivo del ensayo deja muchos elementos sin concluir o al arbitrio del lector y sus decisiones, “...lo cual implica una desestructura y uso de recursos parabólicos que impulsan al lector a desarrollar una competencia intertextual ante el fragmento y de ese modo completar el sentido de forma externa al contenido” (Suleiman 1997: 468-489). Se torna entonces necesaria una enciclopedia nutrida y solvente, lista para responder a un mensaje que elude y se resiste a toda representación reduccionista.

El lector del ensayo está llamado a desarrollar una competencia que pueda enfrentar la cita sin entrecomillado y la interrupción o quiebre forzado de ideas tradicionalmente continuas y supeditadas por jerarquía, de modo que existe la labor de compenetrarse con los procesos dialógicos que el texto establece con otras realidades. En tal caso, el texto literario no se considera aislado de los demás hechos textuales y no textuales, sino en activa interrelación con ellos, articulando disciplinas, contextualizando datos, relacionando y, como plantea Carrasco, "tratando de dar sentido a elementos, situaciones y momentos históricos distintos, medios verbales y no verbales, literarios y de otras formas de discursividad” (2002: 199-210). Este hecho ha alterado también el modo de leer, mutando tanto el proceso privado referido a las expectativas particulares del lector como al rol de la teoría y metodología de interpretación.

La desestructura y apertura de los temas tiene como correlato el carácter parabólico ${ }^{3}$ del texto. Tal como se indica aludiendo a Suleiman, es una respuesta proporcional a la síntesis, la cual tiende al escamoteo y omisión de pasajes, fragmentación de lo enunciado y una exégesis lectora que remite a la parodia y la subversión. Esto podemos graficarlo desde la perspectiva de Cerda en un plano axiológico,

\footnotetext{
Un análisis transtextual aplicado al quehacer del escritor chileno demuestra en cada página de su obra un intenso y consecuente diálogo con la literatura en general; éste se libra gracias a la riqueza y apertura de amplísimas relaciones las que paradójicamente se han acrecentado tras su temprana e intempestiva muerte, involucrándolo como protagonista o testigo en la ficción, actante o narrador en la obra de sus pares (por ejemplo, Soldados de Salamina de Javier Cercas).

3 Este complejo sistema de superposiciones, transtextualidades, inversiones y alusiones, tienen como propósito hacer coherentes el sentido literal y el figurado. El lector deberá reducir los significados retóricos, comprimir la plurisignificación a partir del sentido literal y concluir una "regla de acción" (Suleiman 1977). En otros términos, acoger los valores de la enunciación y excluir los valores de la historia oficial.
} 
visualizando una compresión de los contenidos enciclopédicos y valóricos del autor, los cuales en lugar de entender la sociedad o mundo como cohesión, se refunden en una voz indefinible, carente de género, edad y rostro, ambigua al punto de llegar a la contradicción y la mudez. Esta paradoja genera una búsqueda de sentido más allá de lo inmediato: el texto autosuficiente. El ensayo, al no aludir a una realidad concreta e inmediata, tiene sustento en la propia palabra.

Podemos agregar que la búsqueda del fragmentarismo se da en distintos planos; en principio, tal como señala Barrenechea, es una "forma de quebrar el pacto mimético y la unidad textual” (1982: 377-381), síntoma de la carencia de lógica e imperio de vías transversales que atentan contra todo orden taxativo. En lo productivo del ensayo, la fragmentación apunta también hacia una cultura de lo periférico, visión desprovista del poder hegemónico de los grandes relatos; en tal grado, el fragmentarismo, tal como expone Carrasco, contribuye junto a los otros dos ejes en estudio, la intertextualidad e ironía, a la falta de clausura en lo enunciado y a una sensación de semiosis latente. Semejante corte de las excedencias posibilita la extensión del plano semántico más allá del texto. Es un tema de encuadre y tanto los contenidos escamoteados como los aludidos se llenan de significado y guían hacia un final por completar. Las implicaturas cobran vigor y se solucionan en el código del lector.

\subsubsection{Intertextualidad}

En la medida que el ensayo esté regularmente constituido a partir de la lectura de otro escrito, la contemplación de una obra artística o la íntima resonancia de una idea ajena ha predispuesto siempre a pensar que el ensayo fue escrito únicamente para explicar, comentar o juzgar los temas. Representación descuidada que ignora una primera faceta de la intertextualidad ${ }^{4}$ y que Cerda destaca en sus escritos; la idea que propone es que el ensayista está por debajo de esa ocupación visible, trabajando consigo mismo. Así lo señaló Montaigne al presentar sus ensayos: uno mismo es la materia preponderante de sus libros. Lukács llamó a eso la ironía esencial del ensayo.

José Alberto de la Fuente, en su artículo referido a la obra de Martín Cerda, llama a ésta ocasionalidad: "La ensayística de Martín Cerda (...) se origina a partir de una circunstancia, de una lectura o de otro escrito. Sus principales características son la ironía (estrategia de enmascaramiento) y la ocasionalidad” (2010: 29-39).

En toda preferencia (literaria, artística, biográfica, epocal) siempre están en juego determinados valores que Walter Benjamin ilustra al afirmar que el deber de todo escritor es impedir que la historia la hagan únicamente los vencedores, porque entonces se convierte en un indecente delirio. Esto implica una polémica con la propia

\footnotetext{
Kristeva (1966), en un ensayo titulado Le mot, le dialogue et le roman, consagrado a Bajtín, expresa que el texto se construye como un mosaico de citas, siendo éste absorción y transformación de otro texto. Barthes (1970) aclara que la intertextualidad no tiene relación con la antigua noción de fuente o influencia, puesto que todo texto ya es un intertexto; en niveles variables, otros textos se encuentran insertos en un texto bajo formas más o menos reconocibles, es decir, los textos pertenecientes a la cultura del texto previo y aquellos de la cultura del entorno. De Beaugrande y Dressler $(1981)$ sostienen que la intertextualidad es uno de los requisitos que debe cumplir un texto para ser considerado texto; determina la manera en que el uso de un cierto texto depende del conocimiento de otros textos. Según estos autores, el término intertextualidad se refiere a la relación de dependencia que se establece entre, por un lado, los procesos de producción y recepción de un texto determinado y, por otro, el conocimiento que tengan los participantes en la interacción comunicativa de otros textos anteriores relacionados con él.
} 
situación histórica, artística y vital, y es lo que se ha llamado infratexto, ${ }^{5}$ por ende, la elección de determinada cultura por el autor no obedece sólo a una curiosidad intelectual, sino, además, al proyecto de llegar a identificarse probablemente con una forma de vida que fuese capaz de compensar imaginariamente el radical desajuste con la vida de su tiempo. Signos que constituyen el diálogo con un segundo e incluso tercer texto sumergido, encubierto o tapado por el texto explícito de los artículos ensayísticos y el grueso de un universo literario.

Cerda nos dice: "El ensayo está, de este modo, siempre "atado" al objeto que lo ocasiona (libro, obra de arte, forma de vida), pero a la vez, siempre lo sobrepasa sin llegar nunca a la fría perfección del sistema” (Cerda 1982: 5). El ensayo es, en otros términos, siempre ocasional, como indica De la Fuente, en el sentido que está regularmente ocasionado por un objeto, pero siempre de manera provisoria, en el sentido que no cesa nunca de buscar la forma cerrada del sistema. Esto explica que, en cada ensayo, donde los demás descubren valores, verdades, ideales y certezas, el ensayista sólo encuentra problemas, incertidumbres y despistes.

Lo que suele reprocharse al ensayista es, de hecho, que cada vez que se ocupa de pensar un objeto (texto, obra de arte, forma de vida), siempre despiensa al mismo tiempo lo pensado anteriormente sobre ese objeto, introduciendo, de este modo, una doble negación en el orden de las cosas. Desde Montaigne hasta hoy, efectivamente, el ensayista descubre en cada orden de cosas (vida propia, organización familiar, sistema laboral, estructura social) no una armonía, un cuerpo orgánico, sino más bien una pluralidad de conflictos, desequilibrios y contradicciones; allí está la raíz de su escritura, en la suma e interacción de todos esos elementos, intertextos que se invocan y exorcizan.

Basados en Bloome y Egan-Robertson podemos agregar, desde una perspectiva semiótico-social, que "la intertextualidad implica un potencial para construir significado, lo que a su vez tiene funciones interpersonales, ideacionales y textuales. La intertextualidad no se limita a referencias explícitas o implícitas a otros textos, puesto que puede ocurrir en distintos niveles (palabras, estructura de textos, registros, géneros y contextos) y de distintas maneras (mezcla de registros, contenidos, géneros y situaciones)” (1993: 24).

\subsubsection{Ironía}

Martín Cerda aborda la ironía como una actitud a la hora de escribir, modo y método que va profundamente ligado al quehacer discontinuo que plantea la fragmentación. Citando a Blanchot, Cerda expresa que "Sólo la ironía puede hacer coincidir el discurso con el silencio, el juego con la seriedad, la exigencia declaratoria, y hasta oracular, con la indecisión de un pensamiento inestable y dividido, y finalmente, para el espíritu, la obligación de ser sistemático con el horror del sistema” (1982: 28).

De la Fuente, por su parte, a propósito de la obra de Cerda, se detiene en la idea de ironía en los siguientes términos: “... .la ironía es el rasgo esencial, preguntas encubiertas o disimuladas que enderezan las costumbres, opiniones y sucesos de una época, anticipando la crítica a los rasgos más acusados de una determinada sociedad” (2010: 29-39).

\footnotetext{
"El infratexto, como lo entiende Martín Cerda en La palabra quebrada, es la memoria como una forma de saber, como un re-conocimiento de nuestra humanidad, como un recuerdo remanente de la manada y como una invocación a la más primaria sabiduría: la del milenario elefante. La memoria se transforma así en la superación del desgarro, de la ira, de la culpa, de la vergüenza, del trauma, al fin: la resiliencia del animal que a fin de cuenta somos. Y con mucho humor y tanta ternura también” (Harris 2009: 238).
} 
Para Lukács, en cambio, la ironía del ensayista consiste en estar aparentemente siempre ocupado de libros, imágenes, objetos artísticos o cosas mínimas, cuando, en verdad, está siempre hablando de esas cuestiones últimas de la vida que, de una manera u otra, lo preocupan, inquietan o atormentan. La ironía es, de este modo, la estrategia o recurso que emplea el ensayista para enmascarar sus preguntas más radicales bajo el aspecto de una glosa o digresión ocasional, y por eso ocurre que cuando más lejano el autor parece de la vida, más doliente y quemante es su proximidad.

Podemos delimitar estas ideas con la definición etimológica que Cerda entrega frente a la palabra ironía: “eironeia fue, para los griegos, lo que hoy llamamos disimulo, y derivaba de éromai (yo pregunto), y constituye, por lo tanto, una interrogación enmascarada o, como dice el diccionario, el "arte de preguntar fingiendo ignorancia" (1982: 24).

Lo verdaderamente esencial en cada ensayo no reside, en consecuencia, en el objeto de que se ocupa, sino, más bien, en las preguntas a que se somete discreta y, a la vez, radicalmente, porque esas preguntas suelen tocar la concepción del mundo en su desnuda pureza, son ellas las que permiten al ensayista ir reduciendo a escombros la fachada altanera de los pensamientos convertidos en tópicos o doxas y, a la vez, anunciar el perfil inédito de las cosas que promete el futuro.

\section{ESTRATEGIAS TEXTUALES EN EL ENSAYO "EL EXILIO Y LA LITERATURA"Y SU PROCESO DE ACTUALIZACIÓN}

Para efectos de análisis, metodológicamente centraremos la lectura de "El Exilio y la Literatura” (en adelante EL) de Bolaño vinculando el texto con cada una de las estrategias que Cerda utiliza para caracterizar el ensayo, priorizando, desde luego, las alteraciones que éstas provocan en los movimientos cooperativos del lector empírico en el contexto del modelo metatextual propuesto por Eco.

\subsection{Fragmentación frente a las reglas de correferencia y las estructuras ideológicas}

El ensayo EL de Bolaño altera las reglas de correferencia y estructuras ideológicas, condicionando el recorrido e interpretación que hagamos del texto. De este modo, podemos entender el mosaico de situaciones que se plantean de forma errática en el texto de Bolaño, la cantidad desmesurada de información y en apariencia inconexa, los saltos en la modalidad del discurso y asimismo la variación que el autor va procurando a la temática, pues si bien el título propone al lector empírico un tema bastante delimitado, y en ese grado determina o al menos orienta las expectativas frente a la materia que el destinatario eventual deberá enfrentar -el exilio y su relación con la literatura-, la realización final del texto flexibiliza y muta el contenido y recorrido a realizar. Este fenómeno promueve en el lector empírico ingenuo la idea de encontrarse ante un cuento, crónica vivencial o incluso divagación propia de un diario de vida más que frente a un ensayo.

Esta respuesta a la lectura está motivada principalmente por la ruptura de unidad del tema central, algo que se procura evitar en los llamados textos “objetivos" , los cuales persiguen entregar una verdad de modo directo que un lector actualiza en términos lineales, con un centro definido, lo que a su vez responde a una lógica 
cultural que podemos asimilar al modelo que plantea el árbol de Porfirio. ${ }^{6}$ Éste es un árbol sólo de diferencias y como consecuencia puede ser reorganizado constantemente conforme a diversas perspectivas jerárquicas que lo constituyen. Como principio para estructurar mapas mentales, tiende a limitar el estudio del texto a los conceptos enunciados y elimina el rol que juega el contexto o información alternativa, pues el lector se identifica con una visión plana del texto que se resuelve en la actualización de lo explícito y propuesto de antemano, de modo que la búsqueda de referencias se confunde con un rastreo de fuentes más generales, lo cual satisface el mito de la filiación en lugar de proponer inferencias, contrastes o copresencias.

De este modo, los géneros y las especies porfirianas son fantasmas verbales que encubren la verdadera naturaleza del árbol y del universo que éste representa: un universo de puras diferencias. Este árbol de sólo diferencias plantea un ulterior problema: las diferencias son accidentes y los accidentes son infinitos o al menos indefinidos en número, "con lo que el árbol deja de ser un diccionario para transformarse en una enciclopedia, toda vez que está compuesto por elementos de conocimiento del mundo.” Además, "las diferencias pueden ser reorganizadas continuamente según la descripción conforme a la cual se considera determinado sujeto. El árbol es una estructura sensible a los contextos, no un diccionario absoluto" (Eco 1984: 125-126).

Por ello, una mirada lineal y básica de la lectura e interpretación, dada por el uso de textos construidos bajo el modelo de Porfirio, no permite que el lector desarrolle una enciclopedia o competencia intertextual que aliente la cooperación activa a través de paseos inferenciales, todo lo contrario, busca la clasificación y procesos que van de lo general a lo particular en una red limitada de significación.

La enciclopedia, como concepto que representa la base del pensamiento de Eco y su modelo metatextual, es para el lector la red de textos a los cuales puede recurrir y con los cuales puede establecer vínculos solidarios de co-interpretación, incluso si éstos son inesperados o abren el entramado hacia otras realidades. Saleta de Salvador Agra lo plantea en su ensayo "La semiosis ilimitada del hipertexto como texto en acción” (2009) y nos informa que Eco estudia la noción enciclopédica como una red de estructuras excéntricas, no ramificadas, no arbóreas sino rizomáticas con infinidad de temas que se entrecruzan.

En nuestro caso, el hipertexto ${ }^{7}$ es una forma hiperbolizada que asume la intertextualidad y el fragmento; lo indispensable es la forma en que deviene la enciclopedia (cfr. Eco 1984: 136 y ss.). Frente a la representación semántica del diccionario, de equivalencias fijas, de ramas rígidas, la naturaleza rizomática de la enciclopedia se caracteriza por sus relaciones mutables. Por tanto, los textos ensayísticos más complejos que Cerda caracteriza refiriéndose a Barthes, Benjamin,

Eco dice: “...toda la edad media se encuentra dominada por la persuasión -sin duda inconsciente- de que el árbol reproduce la estructura de la realidad (sospecha neoplatónica de la que no se ven libres ni los más rigurosos aristotélicos)” (1985:114). El árbol, constrúyalo Porfirio como lo construya, según Eco, termina fragmentándose en infinitas diferencias, sin orden jerárquico alguno. El diccionario por su propia dinámica interior se ve convertido en enciclopedia.

\footnotetext{
Este comportamiento teórico de los signos, su recursividad infinita, tiene en el hipertexto una versión plástica. Su capacidad de conexión, reenviando ilimitadamente un signo a un signo sucesivo, ejemplifica la progresión continua que sin linealidad preestablecida y sin centro definido (posibilitado por la variabilidad en el orden del recorrido hipertextual, o lo que es lo mismo, por el cambio de la posición lógica, anteriormente descrita) traza, al igual que ocurre en la semiosis ilimitada, el mapa móvil de la vida de los signos.
} 
Nietzsche y Kant gozan claramente de una actitud descentralizadora, aforística y giran en torno al fragmento como ideario del pensamiento y por ende al rizoma múltiple y descentrado como base para la (des)estructuración de la escritura. Ejemplo de esta situación es el siguiente fragmento citado de EL:

En 1978 o tal vez en 1979 el poeta mexicano Mario Santiago, de regreso de Israel, pasó unos días en esta ciudad. Según me contó él mismo, un día la policía lo detuvo y luego fue expulsado. En la orden de expulsión se le conminaba a no regresar a Austria hasta 1984, una fecha que le parecía significativa y divertida a Mario y que hoy también me lo parece a mí. George Orwell no sólo es uno de los escritores remarcables del siglo XX, sino también y sobre todo y mayormente un hombre valiente y bueno (2001: 42-44, cursivas nuestras).

La cita nos permite observar cómo Bolaño salta de un tema inicial, las vivencias de Mario Santiago, poeta mexicano exiliado de Viena, a otra información, en apariencia inconexa: la alusión al escritor inglés George Orwell y su valoración como escritor remarcable del siglo XX. No hay una marca explícita para el lector empírico que sirva para hacer la vinculación y co-interpretación de estas dos ideas en función del significado general del texto: el exilio y su relación con la literatura; esa tarea es parte de la semiosis latente que corresponde descodificar al destinatario en su llamado a cooperar.

El nexo requiere, por tanto, de ciertos códigos marcados por una enciclopedia literaria, y hace uso de una fecha, 1984, ligada a la historia y devenir de su compañero el poeta mexicano Mario Santiago que no puede volver hasta dicho año a Viena; dato curioso para Bolaño y su compañero, pues la fecha trae a la memoria de los conocedores de Orwell y la literatura universal, la novela de ciencia ficción distópica titulada 1984 y que en sus páginas nos muestra el retrato ficticio de una de las peores maquinarias totalitarias de control y manipulación de la verdad (el Gran Hermano). La sutil alusión a la novela de Orwell aparece sin una marca explícita o nota al pie de página. Estos cambios e interrelación de temáticas que superan la enciclopedia del lector promedio, quiebran la linealidad del discurso.

El siguiente esquema nuestro, basado en los estudios de Julien Pacotte en Le réseau arborescent, schème primordial de la pensée (1937), revela cómo opera de forma empírica la fragmentación como estrategia textual en el texto EL:

\section{Esquema modelo de EL como lógica rizomática y fragmentaria}

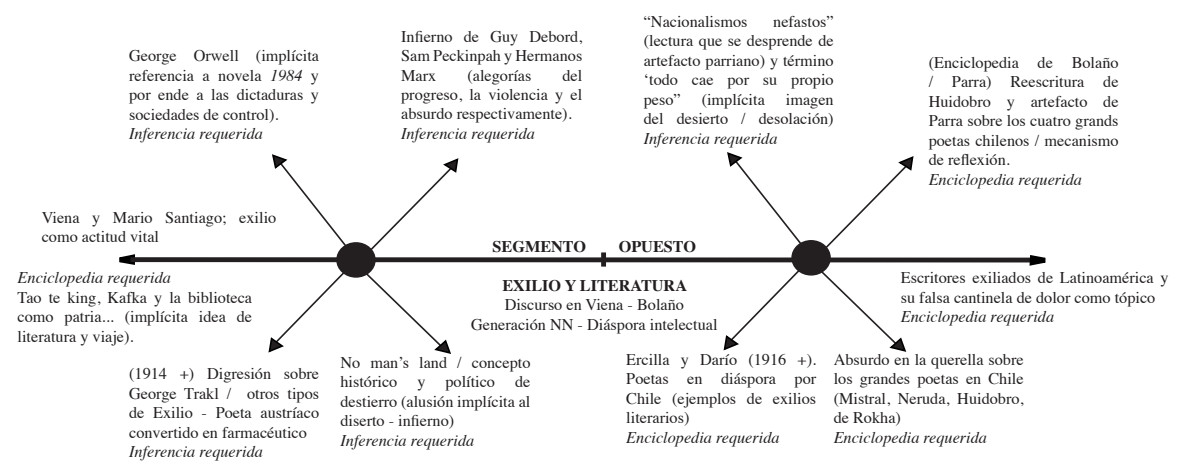


El esquema da cuenta de un rizoma en que los temas se cruzan y autorrefieren, pero a la vez se dispersan de forma insospechada, exigiendo al lector una enciclopedia o información previa fuera del texto, así como también procesos de inferencia que invitan a salir de lo explícito y literal (cfr. Gilles Deleuze y Feliz Guattari 1988: 13-15).

Es por estos mecanismos lógicos que ante un texto como EL, la respuesta típica del lector ingenuo que actualiza desde los parámetros del árbol de Porfirio, surge una actividad cooperativa básica e interpretación que delata la insuficiente competencia interpretativa en donde el lector puede quedar atrapado o excluido, en términos de Eco.

En cuanto a la estructura de EL, podemos agregar que gracias a la fragmentación no sólo se tensiona y quiebra el tema, sino que esta peculiaridad da pie para ingresar al terreno de la ironía y desacralización de las grandes figuras y mitos de la sociedad; en el caso del ensayo de Roberto Bolaño, la desmitificación afecta a la poesía y su apreciación dentro de la sociedad chilena, usando como pilar la imagen de Nicanor Parra y sus Artefactos, por ende, en el caso particular de EL, la fragmentación se expone, tal como lo indica Martín Cerda, como un modo de asumir y valorar el mundo, en este caso particular, una manera de entender la literatura y una situación tan cercana a la historia reciente de Chile y sus escritores: el extrañamiento. El lector, en esa medida, debe enfrentarse en el ensayo en cuestión a una escritura que se aparta de lo lineal, que se desenvuelve en un caos de información que, lejos de plantear una verdad o certeza, busca extender múltiples interrogantes y caminos sobre la base de una médula que se cruza y multiplica.

El texto ensayístico de Bolaño surge de una premisa general y clara, la invitación que le hacen al autor nacional a referirse en Viena al tema exilio y literatura. Este escritor de la generación NN de Chile -diáspora intelectual de nuestra nación (enciclopedia intertextual requerida, biografía y otros textos del autor que dan cuenta de esta realidad, como el cuento "Detectives" o las novelas Nocturno de Chile o Los Detectives Salvajes)- hace un ensayo rizomático que parte enunciando en este entramado sobre exilio y literatura una anécdota familiar: la vida de Mario Santiago Papasquiaro, poeta mexicano que sufre un destierro en la misma ciudad que le cursará la invitación a Bolaño. Esta información es explícita para el lector; sin embargo, el autor la dota de elementos implícitos que le sirven para definir una actitud vital del exilio, y alude al Tao Te King y la frase "Sin salir de mi casa conozco el mundo". Frase contradictoria para un escritor nómade y errante (enciclopedia intertextual requerida), pues Bolaño siempre alude al significado de la literatura en relación al viaje: "El viaje de la literatura, como el de Ulises, no tiene retorno". Y que encuentra su par en el verso "Si he de vivir (que sea sin timón y en el delirio)" del poeta Mario Santiago (Ulises Lima en la novela Los Detectives Salvajes), texto que sirve a la vez de epígrafe a la novela Pista de Hielo de Bolaño. Por ende, el significado de la frase del Tao Te King puede entenderse también como un viaje interior, de aislamiento del mundo, pero de autoconocimiento y de búsqueda personal (inferencia requerida).

Kafka, en ese sentido, aparece en un fragmento de EL, más que como autor, como un paradigma o alegoría de este viaje (cfr. esta idea en "Literatura + enfermedad= enfermedad”, 2003: 2). En este punto, el lector lineal ya ha perdido el rastro al texto, pues Bolaño ha ido dispersando la idea de exilio y literatura, alejándose de un concepto unívoco y de un esquema de subtemas jerarquizados.

La situación se complica aún más cuando, saltando los deícticos, Bolaño alude a Orwell -como ya dijéramos-, lo pontifica como una voz clave del siglo XX sin mediar 
una relación causal directa entre la presencia textual de este novelista en el ensayo y la frase inmediatamente anterior. Orwell, autor de la novela distópica 1984, cuyo título es homónimo a la fecha en que Mario Santiago puede retornar a Viena -aunque este retorno no se verifica. Mario Santiago vuelve a México como literalmente nos indica Bolaño (2001), y muere allí en condiciones trágicas y miserables, cumpliendo su destino de autor situado en los extramuros del poder, un exiliado, en otras palabras, que vive y muere en los márgenes de un infierno, pero no cualquier infierno, sino el asimilable a los artistas y pensadores como Guy Debord, Sam Peckinpah y los Hermanos Marx.

Si el lector posee la enciclopedia y referencias puede inferir que cada uno de éstos representa un adjetivo para ese infierno. Debord, situacionista y autor de $L a$ sociedad del espectáculo, da cuenta del progreso y su deshumanización; Peckinpah, director de violentos filmes como La pandilla Salvaje o Perros de Paja, representa la crueldad, y los cómicos del absurdo, Groucho Marx y compañía, dan cuenta del sin sentido, todo esto en un No man's land que no necesita de una orden de exilio directa de un gobierno, sino que es la desolación en que diariamente mueren miles de anónimos que, como Mario Santiago, por voluntad, o como las mujeres de Juárez (protagonistas de la novela póstuma de Bolaño, 2666 - enciclopedia intertextual requerida), mueren por no representar un sujeto de valor para el poder, desapareciendo en la más completa indiferencia.

El no man's land explícito que Bolaño define en el ensayo como un erial o yermo, gana mayor sentido si vinculamos esa idea, para nada caprichosa o sin importancia, con lo que Alexis Candia dice en su estudio sobre 2666. Candia agrega que la estética del mal de Bolaño tiene como asentamiento un espacio físico que le sirve al autor de sustento material, en este caso, se trata de Santa Teresa, que toma como referente Ciudad Juárez en la frontera de México con Estados Unidos, infame región del país del norte que, a causa de los continuos y sistemáticos asesinatos de más de 300 mujeres, el escritor chileno calificó en su última entrevista, concedida a Mónica Maristain de la revista Playboy, como un verdadero infierno: "Ciudad Juárez es nuestra maldición y nuestro espejo, el espejo desasosegado de nuestras frustraciones y de nuestra infame interpretación de la libertad y de nuestros deseos” (2010: 25).

Rápidamente, el ensayo de Bolaño va mutando su significado en función de cada elemento aludido y escamoteado, pero esto no termina en esa primera red de relaciones; en el segmento opuesto de EL encontramos la figura de artistas que lucran con la imagen autoflagelante del exiliado, una noción que se contrapone a la actitud vital del exilio, pero no por eso excluida o menos detallada en la lectura, pues contrario al modelo de Porfirio, en el ensayo de Bolaño no estamos ante una mera diferencia, sino ante otra temática que importa interpretar en beneficio del sentido global; por ende, de esta idea se desprenden otras que rozan lo previamente analizado y, a su vez, amplían la lectura general del ensayo potenciando significados en torno a la literatura y el viaje y también la consideración de la biblioteca como patria; todo esto sutilmente enunciado, al igual que la alusión a Orwell, introducido ahora a la lectura de modo inesperado.

Con Bolaño, un político puede sufrir en carne viva el exilio, pues no puede medrar fuera del país de origen; un escritor no debiera tener esa debilidad, pues sólo tiene como patria a su familia y biblioteca, y esa biblioteca puede ser mental, por ende, no cree en los escritores que se apropian del tópico del exiliado para crear desde esa condición una obra (inferencias requeridas). 
Al detallar el proceder de autores exiliados que lucran con su condición, nos obliga a retroceder a una noción de biblioteca como patria, aludiendo desde luego a la propia biblioteca, fuente de su educación sentimental; desde allí, proyecta nuevos planteamientos para su ensayo, uno clave es la presencia de Nicanor Parra, el chileno creador de la antipoesía (enciclopedia requerida), pues Parra, junto a George Perec, Borges y Enrique Lihn, son una suerte de autores de cabecera de Bolaño, y éste no sólo los hace parte de la ficción en poemas como Un paseo por la literatura o novelas como Amuleto, sino que dedica sendos ensayos a sus trayectorias, trabajos que han sido recopilados en su libro Entre Paréntesis (2004).

De Parra, Bolaño toma el Artefacto como construcción poética para complementar su idea y extender la discusión sobre el exilio en función del arte; se detiene en un artefacto en especial, la reescritura que Nicanor hace de un conocido poema breve de Vicente Huidobro; de este modo va delimitando también la querella nacional sobre los cuatro grandes poetas, querella que además va en directa relación con la versión/ diversión de Parra en que satiriza esta polémica que Bolaño encuentra inútil, al punto de compararla con el juego infantil de la silla musical, en que a cinco nombres le tocan sólo cuatro escaños, quedando siempre uno fuera, de acuerdo al contexto y arbitrio de quien invoque esta pugna de poetas.

Parra, en lugar de detenerse en la imagen de Neruda, Mistral, Huidobro y De Rokha, enumera ocupando el rol de los cuatro grandes poetas chilenos sólo a Ercilla y Rubén Darío, ambos extranjeros de paso por el país, pero con una obra fecunda en relación a nuestra tierra: La Araucana y Azul, respectivamente. Bolaño entrega de modo directo esta información; sin embargo, la relación, que no es explícita, sino más bien una inferencia dada al lector, es la de la literatura-viaje, pues tanto Ercilla como Darío fueron autores que construyeron una obra lejos de casa y siempre de camino a un destino incierto, por eso, Bolaño alude de modo tangencial a estos dos autores coincidiendo con lo que dice también Mario Santiago: ser presa de un exilio voluntario. En EL, Bolaño escribe: "En fin, tenemos a Rubén Darío y tenemos a Alonso de Ercilla, que son los cuatro grandes poetas chilenos, y tenemos lo primero que nos enseña el poema de Parra, es decir, que no tenemos ni a Darío ni a Ercilla, que no podemos apropiarnos de ellos, sólo leerlos, que ya es bastante” (Bolaño 2001). Ercilla, por su parte, está presente en otros textos de Bolaño vinculados a la noción de viaje y literatura y, asimismo, como parte de otro tema importante para la biografía del autor: la enfermedad, a la cual ya nos referimos al denotar la presencia de Kafka.

Estos nexos, sin duda, nos hacen retroceder de modo inesperado a la imagen de Mario Santiago y dota de otro significado su vida y muerte; también coopera en el desarrollo de la noción de No Man's Land, pues, como vimos, esta idea no sólo se refiere al destierro político, sino más bien a una imagen de desolación, de desierto y esas más o menos son las condiciones dadas de quienes asumen este viaje sin timón y en el delirio, como reza el verso de Mario Santiago, hipotecando su vida en función de una obra, su arte. Darío no es la excepción y también es víctima de ese infierno que estructura la ignominia del poder.

La fecha de muerte de Rubén Darío, 1916, no escapa a las digresiones y nexos temáticos que Bolaño establece desde el fragmento; a propósito de esta mención, el autor del ensayo recuerda la muerte de otro importante poeta universal, el austríaco Georg Trakl, que falleció en 1914. Bolaño presenta explícitamente esta digresión, una alusión para nada casual, pues Trakl, además, está vinculado por nacimiento al 
país europeo desde el cual emana la invitación que da origen al ensayo. De cualquier modo, en términos más sutiles, Trakl representa otro tipo de exilio o destierro, el de un joven que abandona sus estudios para iniciar una labor extraña y alienante: la de un farmacéutico. Hay que agregar a esto un conflicto ético/creativo que Bolaño vincula en su obra 2666 a esta figura de un hombre alienado por su trabajo de funcionario de botica (enciclopedia requerida).

Bolaño nos entrega entonces, a punta de fragmentos dispersos, nociones interrelacionadas del exilio que dialogan con sus otras obras y con gran parte de la literatura universal y la historia cultural de occidente, atreviéndose a introducir imágenes proféticas y apocalípticas del camino que sigue nuestro continente. Rizoma de sentidos que sería imposible bajo una lógica basada en el paradigma de Porfirio. No podemos ignorar, además, las peripecias vitales y artísticas de Darío frente al poder. Estas son muy semejantes a las experimentadas por Mario Santiago y desde luego a las sufridas también por el mismo Bolaño (no es casualidad que ambos sean los protagonistas enmascarados de la premiada novela de Bolaño, Los Detectives Salvajes, bajo los alter ego de Ulises Lima y Arturo Belano -enciclopedia requerida).

En esa medida, como se expresa textualmente en EL, "los mensajes ocultos que el azar o ese monstruo aún más salvaje que es la causalidad enviaba al poeta mexicano y por intermedio de éste me enviaba a mí” (Bolaño 2001); nota explícita del ensayo, sin embargo, perdida entre el cúmulo de informaciones que el texto nos entrega.

Esta nota cobra mayor fuerza si es que inferimos, apoyados por los datos que nos proporciona el universo textual de Bolaño, el cruce entre su novelística, poesía, relatos y ensayos, bajo la figura de Mario Santiago/Ulises Lima, pues todo lo enunciado toca de algún modo el perfil ético y estético del poeta mexicano; éste, de algún modo, afecta al escritor chileno y representa en gran medida lo pensado y la cosmovisión profunda del ideario creativo y crítico que proyectan sus textos y que afirma sin desparpajo dentro de EL: "el nacionalismo es nefasto y cae por su propio peso, no sé si se entenderá el término caer por su propio peso, imaginaos una estatua hecha de mierda que se hunde lentamente en el desierto, bueno, eso es caer por su propio peso" (Bolaño 2001).

Esta aseveración se desprende del artefacto de Parra, al que Bolaño atribuye, por encima de todo, el rol de un arma capaz de dinamitar la falta de conciencia ciudadana del chileno promedio, ayudándolo a ser más reflexivo y crítico de las insulsas pugnas en que perdemos tiempo; no sólo las que buscan hacer un ranking de sus mejores creadores, sino también las que nos separan de nuestros vecinos latinoamericanos, de modo que el tema de la frontera y la desolación de un continente aparece de nuevo como otra de las formas de exilio que el autor pretende plantear: la del infierno que hemos construido en base a esta utopía americana (Cfr. también esta idea en "Un paseo por la Literatura”, Bolaño 2000: 77; enciclopedia requerida).

Se puede concluir, basado en esta lectura, que queda claro que el tema central o topic $^{8}$ del texto es la literatura y las imbricaciones que este arte tiene con el exilio asumido como forma de vida, específicamente como una actitud, tal como el autor lo evidencia desde un comienzo en su escrito.

El topic es un instrumento metatextual, un esquema abductivo que propone el lector, mientras que la fábula forma parte del contenido del texto (se trata de una oposición entre instrumento pragmático y estructura semántica), en términos de U. Eco (1986: 126). 
El modo de abordar las ideas es el fragmento y su correlato lógico, el rizoma, una especie de espejo roto en el cual el lector puede contemplar, discutir y discurrir entre diversas ampliaciones y reducciones de un mismo reflejo. Por tanto, esta fragmentación pretende acabar con el concepto de exilio como lugar común y fuente nutricia para los poetas y escritores que buscan aprovechar su contexto y adversidad como divisa o tribuna. El fragmento no sólo es una técnica para vincular ideas y ampliar el diálogo con sus lectores, es al mismo tiempo un mecanismo para ironizar y desacreditar visiones de mundo y mitos.

\subsection{Intertextualidad frente al diccionario básico, las circunstancias de enunciación y las estructuras ideológicas}

Para Koch y Travaglia "hay intertextualidad en la medida en que, para el procesamiento cognitivo de un texto, se recurre al conocimiento previo de otros textos" (2000: 75). La intertextualidad es un hipertexto; por ejemplo, permite que se hagan conexiones entre textos o entre partes de un mismo texto, volviendo visible una relación que siempre existió y dando al lector la posibilidad de definir cuál será el inicio y el fin del texto, promoviendo la creación de un "nuevo texto".

Si vinculamos estos planteamientos sobre la intertextualidad a los fragmentos que se dispersan de la idea central -exilio y literatura-, podemos establecer una red infinita de relaciones que comunica la obra del autor con su biblioteca personal, la memoria y la vida, autores de la literatura universal, cine, historia, política, derechos humanos, tópicos del arte y más. Este fenómeno de cruces y redes dispersas, si bien parece caótico a simple vista, es parte de una estructura rizomática y abierta que alienta la flexibilidad y multiplicidad de significados, interactuando de modo exploratorio y discontinuo.

Se trata de nodos que, ciertamente, vinculan de modo recursivo e inesperado presencias, citas, fragmentos y espacios que requieren de una enciclopedia que va más allá del diccionario básico, lo que sin duda pone en movimiento referencias ideológicas, literales y también estéticas que dan cuenta de saltos que al volver al tema, en apariencia central, modifican el significado básico del tópico. Entonces, la búsqueda del sentido se actualiza y reformula con cada nueva entrada, con cada recorrido y actividad cooperativa que desplegamos como lector.

De este modo, haciendo un ejercicio simple de cruce de discursos y voces, podemos constatar la dinámica que Bolaño promueve con su escritura ensayística fragmentaria e intertextual, multiplicaciones semánticas y la mutación de casilleros que, como se puede apreciar en el esquema (v. supra), se entrelazan afectándose entre sí, de manera que estamos ante una realidad textual interdependiente cuyas líneas colindantes sólo son vistas y trazadas por el lector que va más allá de una lógica jerarquizada y que se aboca a la tarea de reconstruir la trayectoria del texto cuantas veces sea necesario y demandado para comprender la total complejidad de lo expresado.

Además, podemos delimitar algunas de estas relaciones intertextuales y notar ciertos puntos que se repiten a lo largo de la obra del autor como parte de su educación sentimental, lo que a su vez nos da pie a pensar en un dialogismo intertextual en que el escritor se autorrefiere y prefiere por encima del lector neófito a uno enterado de las normas que su universo textual contiene y promueve. En el caso de Bolaño, estamos ante un universo que se entrelaza y vincula por múltiples vías, estando compuesto por 
poemarios, colecciones de cuentos, novelas muy extensas como 2666 o Los Detectives Salvajes y ensayos.

En este sentido, tenemos la alusión perpetua a Chile, su literatura e historia política y social reciente, sin ignorar las pendencias y tipos humanos emergentes principalmente producto de la dictadura y la diáspora que afectaron a lo que podría denominarse de algún modo la generación de Bolaño, materias que, en definitiva, son objeto constante de sus reflexiones literarias y nos llevan a entender la matriz del texto y la otra faceta del intertexto, la del dialogismo intertextual ${ }^{9}$.

Bolaño, desde un principio, se aparta de la linealidad y procede a embarcarse en la biografía y peripecias de un amigo escritor a propósito de la mención de Viena, lugar desde el cual emana la invitación a dictar la conferencia sobre el exilio y la literatura. El poeta Mario Santiago y su presencia en el texto no es un factor menor; junto a este poeta, Bolaño fundó el movimiento infrarrealista, y él forma parte de sus novelas, relatos, poemas y ensayos como persona y personaje: relaciones infratextuales e intratextuales tal como lo indica la teoría de Genette. ${ }^{10}$

Bolaño esboza críticas por momentos directas y en otros casos sutiles ante el oficialismo literario y el aprovechamiento político y mediático de los escritores en torno al exilio. Por ende, si atendemos al esquema de fragmentación (rizoma) ya expuesto, podemos realizar el proceso de co-interpretación de cada una de las temáticas en apariencia inconexas con la tesis central del ensayo EL; George Orwell, Trakl, el cine de Sam Peckinpah, el humor de los hermanos Marx, el no man's land, la querella sobre los cuatro grandes poetas chilenos, y las versiones/ diversiones de Nicanor Parra y sus artefactos entre otros, llegando a lecturas más profundas y dialógicas de la temática que se nos presenta como núcleo del texto, siempre y cuando poseamos la competencia intertextual que se nos demanda y la voluntad de cooperación que asume este laberinto de nodos que se bifurcan y dispersan.

En lo cinematográfico, tenemos a Sam Peckinpah y los hermanos Marx que aparecen en un mismo párrafo que el escritor, filósofo y cineasta francés Guy Debord. Todos como alegorías que Bolaño utiliza para graficar un DF-México infernal en que murió su amigo y poeta exiliado, objeto del enunciado.

Sam Peckinpah, por ejemplo, es director de filmes como Straw Dogs o La Pandilla Salvaje y representa en el ideario de Bolaño la violencia. De hecho, no sólo lo menciona en EL, previamente este director aparece como referencia de la brutalidad

\footnotetext{
El lector asiduo a la obra de Bolaño tendrá una perspectiva interpretativa mayor, pues su bibliografía interactúa solidariamente, lo cual permite llenar espacios en blanco, comprender los crossovers o cruces de personajes, ambientes y hechos, y asimilar de mejor manera fenómenos como la reescritura de textos. El lector se hace copartícipe de los hipertextos actualizando de modo abierto y rizomático, tal como plantean Deleuze y Guattari con su modelo antifundacional y epistemológico, "en el que la organización de los elementos no sigue líneas de subordinación jerárquica, sino que cualquier elemento puede afectar o incidir en cualquier otro" (1972: 13). Vale la pena agregar al respecto que "el discurso se encuentra con el discurso del otro en todos los caminos que conducen a su objeto, y no puede no entrar con él en una interacción viva e intensa” (Charaudeau \& Maingueneau 2005: 170).

10 En su forma más restrictiva, tal como la formula el narratólogo Gérard Genette en su obra Palimpsestos. La literatura en segundo grado, la intertextualidad es una modalidad entre algo más extenso denominado transtextualidad, y se trata de "una relación de copresencia entre dos o más textos, es decir, eidéticamente y frecuentemente, como la presencia efectiva de un texto en otro. Su forma más explícita y literal es la cita (con comillas, con o sin referencia precisa)... El plagio, que es una copia no declarada pero literal... La alusión, es decir, un enunciado cuya plena comprensión supone la percepción de su relación con otro enunciado al que remite necesariamente tal o cual de sus inflexiones, no perceptible de otro modo" (1989: 10).
} 
en uno de sus poemas, "El Gusano”, presente en el libro Los Perros Románticos (1998). En cuanto a los cómicos de la película Sopa de Gansos, Groucho y compañía, son una muestra del absurdo y la demencia desbocada, el caos; finalmente, Debord, autor del "Manifiesto Situacionista" y del documental La sociedad del espectáculo, gestor de una obra que grosso modo plantea cómo los sentimientos de alienación podían ser explicados por las fuerzas invasivas del «espectáculo», la naturaleza seductora del capitalismo consumista. Sin duda, una mirada oscura del progreso y del futuro, algo similar a la pesadilla que Orwell plantea en su novela 1984 y que Bolaño alude en su ensayo.

Un texto como el de Bolaño, por motivo de las estrategias que despliega, no puede comprenderse a cabalidad si no es bajo una mirada global de la ideología del autor y aplicando una nutrida enciclopedia intertextual que demanda al lector empírico una ardua actividad cooperativa.

\subsection{Ironía ante las estructuras de mundo y extensiones parentetizadas}

Lo que se altera a grandes rasgos es la expectativa básica del destinatario, por ende, si bien el lector espera un discurso tal como lo concibe la doxa, EL resulta algo totalmente disruptivo, tanto así que se produce un choque que exige al lector la realización de operaciones extensionales más complejas para la actualización. Por su parte, si el texto no le deja asidero para poder considerar lo que se enuncia como real o lo bombardea constantemente con ideas ambiguas, el lector estará siempre en alerta y desconfiando de los cambios de ánimo y actitud del hablante principal.

En el texto de Bolaño esa actitud que va del silencio a la locuacidad, del decir al contra-decir o lisa y llanamente a desdecirse, se nos esboza desde las primeras líneas. Rápidamente, el lector debe adecuarse a un interlocutor dudoso, que vacila y juega con su percepción del tema, no es un hablante directo y seguro, por el contrario, es ambiguo en todas sus afirmaciones y debilita su propio mensaje. No quiere imponer una idea con la determinación de los textos que procuran adoctrinar, más bien quiere dejar en claro que sale de su mutismo por una situación ineludible, la enfrenta pero lo hace con las mismas imprecisiones y desconocimiento que tiene el lector empírico, que debe explorar información desconocida por medio de su enciclopedia muchas veces limitada. Hasta este punto, ambas características, fragmentación e ironía, de algún modo se complementan, el quiebre o caos que impone la fragmentación a la linealidad alimenta la ironía intrínseca del texto, abriendo la polisemia de la infracción y de la duda que impone el interlocutor que sirve de voz al ensayo.

La ironía permite señalar el rol que juega la intrahistoria por encima del gran panorama que nos arrojan las grandes gestas, hitos y personajes. En una primera instancia, Bolaño delimita el tema con vacilación, dudas y de modo burlesco, disminuyendo su idoneidad para tratar el tema o demarcando el equívoco en que incurrirá de modo reiterado por su incapacidad para comprender la lengua inglesa. Ésa ya es una forma de decir y contradecirse; luego adopta el material biográfico y se vale de una anécdota familiar, pues en lugar de dar a conocer una teoría o discurso elevado sobre el tema solicitado, opta por contar parte de la vida y las vicisitudes de su compañero de ruta, Mario Santiago, para dar cuenta de lo que él considera el exilio en su sentido extenso. 


\section{CONCLUSIÓN}

La fragmentación, como forma de escritura, altera las expectativas del lector y modifica la lectura al incidir sobre las reglas de correferencia, saltos de temas y alusiones sin deícticos o marcas explícitas; asimismo, se apunta a las estructuras ideológicas, pues la fragmentación, tal como indica Cerda, radicaliza desde la escritura y el pensamiento una mirada en crisis que el escritor detenta ante la sociedad y sus productos culturales. La ironía, por su parte, afecta las estructuras de mundo y las extensiones parentetizadas, pues pone en jaque la idea de verosimilitud al jugar con la ambigüedad y el descreimiento, al asumir una voz dubitativa y contradictoria no sólo de su propio pensamiento y capacidad, sino que, desde ese ángulo, de un tema acreditado y tópico dentro de nuestra mirada nacional: el exilio y todos los que de algún modo han usufructuado de la posición de víctima.

Por último, la intertextualidad demanda información adicional frente al diccionario básico, hace alusión constante a las circunstancias de enunciación y al llamado infratexto y, en esa medida, también se comprometen las estructuras ideológicas. Por esta razón, todas estas alteraciones en el acto de descodificación del texto, si bien forman parte de las condiciones de comunicación concretas del texto El, reforzando la idea de Eco de Lector Modelo, no es menos cierto que su presencia como elementos retóricos que Bolaño despliega sin tapujos tornan compleja la relación lector/texto y exigen a aquél una cooperación mayor y atenta, pues muchas de ellas superan las fórmulas y regularidades que la doxa ha impuesto como norma formal para la comprensión de lo que se entiende por ensayo o texto divulgativo.

De modo específico, se plantea que la hipótesis del trabajo se confirma en la medida que el Lector Modelo que se (re)construye surge, sin duda, a partir de la organización textual del fragmento como estilo y visión de la realidad y la ironía e intertextualidad como mecanismos de desmitificación de lugares comunes en la escritura.

En todo este esfuerzo, subyace el valor intrínseco del ensayo como género en concordancia con la línea más esencial de la ensayística alemana. Lukacs subrayó en un momento que hoy vemos y valoramos a la tragedia classique, a los griegos y al renacimiento de manera muy distinta a cómo la valoraron y vieron Lessing, Winckelmann, Burckhardt y Nietzsche, y, sin embargo, seguimos leyendo sus admirables ensayos con fruición e interés. El fundamento de esta lectura no depende, en consecuencia, del valor histórico o científico de esos escritos, ni siquiera de una eventual coincidencia de apreciación con el punto de vista adoptado por sus autores, sino de su valor formal. En tal medida, el escritor se vuelve hacia la imaginación, hacia el riesgo mismo de la existencia. Por eso, la validez actual del ensayo es introducir una mirada intermitente en un mundo enmascarado con diferentes ropajes y lenguajes monolíticos y en gran tensión expresiva.

Respecto de Bolaño, lo que se pretende en este escrito es afectar la relación del lector tradicional, adiestrado para buscar una verdad unidimensional o plana, por tanto, su apuesta discursiva y metatextual es hacia la multiplicidad de enfoques que propone: un caleidoscopio y juego de encuadres a fin de dialogar y relativizar un tema que por larga data ha gozado de cierto prestigio y aprovechamiento, la imagen del desterrado, del exiliado.

Bolaño propone de este modo, con el fragmento, la ironía y el espíritu polifónico e intertextual del ensayo, edificar desde el retazo y la duda una lectura que asuma el 
acto de vivir en la escritura como una elección que tiende a los márgenes y la elusión del poder, un vivir en perpetuo exilio y destierro.

\section{OBRAS CITADAS}

Adorno, Theodor. 1962. El ensayo como forma. Notas de Literatura. Barcelona: Ariel.

Ballart, Pere. 1994. Eironeia. La figuración irónica en el discurso literario moderno. Barcelona: Quaderns Crema.

Barrenechea, Ana. 1982. "La ruptura del contrato mimético en la novela contemporánea”. Revista Iberoamericana, No 118-119. Columbia University.

Barthes, Roland. 1974. El placer del texto. Buenos Aires: Siglo XXI. 1986. S/Z. México: Siglo XXI. 1997. Roland Barthes por Roland Barthes. Caracas: Monte Ávila Editores.

Benjamin, Walter. 1967. Ensayos escogidos. Buenos Aires: Sur.

Blanchot, Maurice. 1955. L’space littéraire. El diálogo inconcluso. Caracas: Monte Ávila Editores.

Block de Behar, Lisa. 1990. Dos medios entre dos medios (sobre la representación y sus dualidades). Buenos Aires: Siglo XXI Argentina Editores.

Bloome David. y Egan-Robertson, Ann. 1993. "The Social Construction of Intertextuality in Classroom Reading and Writing Lessons”. Reading Research Quaterly 28 (4): 304-333.

Bolaño, Roberto. (1976). Déjenlo todo nuevamente. Primer manifiesto infrarrealista. En línea; disponible en www.infrarrealismo.com (Visitado el 15/08/ 2011). . 1998. Los perros románticos. España: Lumen. . 2000. Tres. Barcelona: El Acantilado. 2001. "El exilio y la literatura”. Revista Ateneo 15: 42-44. 2002. Amuleto. Barcelona: Anagrama.

. 2003. "Literatura + enfermedad = enfermedad”. En línea; disponible en Página 12, www.pagina12.com.ar/diario/suplementos/libros/10-750.html (visitado el 10/09/2011). . 2004. 2666. Barcelona: Anagrama . 2004. Entre paréntesis. España: Anagrama.

Cabrera, Daniel. (coord.). 2009. Walter Benjamin. La experiencia de una voz crítica, creativa y disidente". Revista Anthropos: Huellas del conocimiento 225, especial dedicado a Walter Benjamin. Barcelona: Revista Antrhopos.

Candia, Alexis. (2006). “2666: la magia y el mal”. Taller de Letras 38: 121-139.

Carrasco, Iván. 2002. "Interdisciplinariedad, interculturalidad y canon en la poesía chilena e hispanoamericana actual”. Estudios Filológicos 37: 199-210.

Cerda, Martín. 1982. La palabra quebrada: Ensayo sobre el ensayo. Valparaíso: UCV Ediciones. 1993. Ideas sobre el ensayo. Santiago: Dibam. 1997. Palabras sobre palabras. Santiago: Dibam.

Charaudeau, Patrick; Maingueneau, Dominique. 2005. Diccionario de análisis del discurso. Buenos Aires: Amorrortu.

De La Fuente, José. 2010. “La ensayística de Martín Cerda”. Universum 25 (2): 29-39.

De Salvador Agra, Saleta. 2009. La semiosis ilimitada del hipertexto como texto en acción. España: Universidad de Santiago de Compostela.

Deleuze, Gilles; Guattari, Félix. 1980. Capitalisme et Schizophrénie 2. Mille Plateaux. París: Minuit. 1988. Mil mesetas. Valencia: Pre-Textos.

Eco, Umberto. 1981. Lector in fabula. Barcelona: Lumen.

_. 1984. Semiótica y filosofía del lenguaje. Barcelona: Lumen. 
1985. De los espejos y otros ensayos. Barcelona: Lumen.

. 1987. "La Línea y el Laberinto: las estructuras del pensamiento latino”. Vuelta sudamericana 9: 18-27.

1990. Los límites de la interpretación. Barcelona: Lumen.

. 2002. Sobre Literatura. Barcelona: Océano, RqueR Editorial.

Genette, Gérard. 1989. Palimpsestos. La literatura en segundo grado. Madrid: Taurus.

Harris, Thomas. 2009. “Elefante de Teresa Calderón: la memoria como saber y resiliencia”. Taller de Letras 44: 213-239.

Koch, Ingedore y Travaglia, Luiz. 2000. Texto e coerência. São Paulo: Cortez.

Lagos, Jorge. 2005. "Si una noche de invierno un viajero, de Italo Calvino: ¿una metáfora de la posmodernidad?”. Estudios Filológicos 40: 107-119.

Lukacs, Georg. 1977. Obras Completas. Barcelona: Grijalbo.

Maristain, Mónica. 2010. La última entrevista a Roberto Bolaño y otras charlas con grandes escritores. México: Axial.

Pacotte, Julien. 1937. Le réseau arborescent, schème primordial de la pensée. Paris: Hermann. Rojas, Daniel. 2009. "El discurso hipertextual como estrategia para la constitución de una memoria universal en la narrativa de Roberto Bolaño”. Realidades Dialogantes. Chile: Cinosargo Ediciones.

Suleiman, Susan. 1977. “L’structura d' aprendissaje”. Poetique 32: 468-489. 